\title{
Synergistic Extraction of Lanthanides(III) with 2-Thenoyltrifluoroacetone and Pyridine as Ion-Pairs and Adducts
}

\author{
Shoichi HIROSE, Masayuki INOUE, and Yuko HASEGAWA* \\ Department of Chemistry, Faculty of Science, Science University of Tokyo, \\ Kagurazaka, Shinjuku-ku, Tokyo, 162-8601, Japan \\ (Received December 11, 2009; Accepted February 6, 2010)
}

The extraction of lanthanides(III) ( $\mathrm{Ln}(\mathrm{III})$ ) from a $0.1 \mathrm{M}$ sodium perchlorate solution with 2-thenoyltrifluoroacetone (Htta, HA) with pyridine (Py) into chloroform was investigated in a thermostatted room at $298 \mathrm{~K}$, in order to examine in detail the variation of the reactivity of $\operatorname{Ln}(\operatorname{tta})_{3}$ with an $\mathrm{N}$-donor ligand across the lanthanide series. It was found that i) The extracted species was the ion-pair (HPy) ${ }^{+} \mathrm{LnA}_{4}{ }^{-}$as well as $\mathrm{LnA}_{3} \mathrm{Py}$ and $\mathrm{LnA}_{3}$. ii) The values of the formation constants of $\mathrm{LnA}_{3}$ adducts with pyridine are smaller than those with carboxylic acids across lanthanide series. iii) The variation in the formation constants of the ion-pairs represented by $\mathrm{Ln}^{3+}+\mathrm{H}^{+}+4 \mathrm{~A}^{-}+\mathrm{Py}_{(\mathrm{o})} \rightleftharpoons(\mathrm{HPy})^{+} \mathrm{LnA}_{4(\mathrm{o})}^{-}$showed a maximum value in the vicinity of $\mathrm{Nd}$ or $\mathrm{Sm}$. Then the separation factor (SF) for Pr from $\mathrm{Sm}$ estimated from the ion-pair extraction is a little larger than that from $\mathrm{LnA}_{3}$. However, the SF calculated for the adduct, $\mathrm{LnA}_{3} \mathrm{Py}$, was not improved on comparison with the $\mathrm{SF}$ for $\mathrm{LnA}_{3}$.

\section{Introduction}

In the synergistic extraction of lanthanides(III) $(\mathrm{Ln}(\mathrm{III}))$ with a $\beta$-diketone and a Lewis base, the extractability is significantly enhanced, due to the adduct formation between tris( $\beta$-diketonato) $\operatorname{Ln}(\mathrm{III})$ and the Lewis base, compared to the extractability in the absence of the Lewis base. Early studies of the synergistic extraction of $\mathrm{Ln}(\mathrm{III})$ have been comprehensively reported wherein $\mathrm{Htta}$ (2-thenoyltrifluoroacetone) was used as the $\beta$-diketone together with Lewis bases with O-donor atoms such as tributyl phosphate and trioctylphosphine oxide[1-3]. The use of carboxylic acids [3-5], tris( $\beta$-diketonato)metal(III) [6,7], linear polyethers [8,9], and crown ethers [10-15] as Lewis bases has also been reported. In general, the extractability of $\operatorname{Ln}(\mathrm{III})$ with the $\beta$-diketone itself increases but the 
adduct formation constants decrease along with the lanthanide atomic number so that the extractability of $\operatorname{Ln}(\mathrm{III})$ do not show large differences across the Ln series, although the extractability of the respective $\mathrm{Ln}(\mathrm{III})$ increased.

Compared to O-donor ligands, relatively little use has been made of N-donor Lewis bases. When Lewis bases with $\mathrm{N}$ donor atoms are used together with Htta, the trend across the Ln series seems to be different from that with $\mathrm{O}$ donor ligands, e.g., the stabilities of the adducts of the $\operatorname{Ln}(\operatorname{tta})_{3}$ chelates with 2,2'-bipyridyl [16,17] or 1,10-phenanthroline [16,18] increase with increasing atomic number across the Ln series. The synergistic extraction behavior of $\mathrm{Ln}$ (III) with pyridines and Htta seems to be somewhat complicated, e. g., it was reported that in the extraction of $\operatorname{Ln}(\mathrm{III})$ [17], the first formation constants of the adducts increased, but the second adduct formation constants decreased with increasing atomic number. In the extraction of $\mathrm{Ln}(\mathrm{III})$ with methylpyridines (B) and Htta, only the ion-pairs consisting of $\operatorname{Ln}(\mathrm{tta})_{4}{ }^{-}$and $(\mathrm{HB})^{+}$were reported as the extracted species $[19,20]$. It was also reported [21] that the association between $\mathrm{Eu}(\mathrm{tta})_{3}$ and 2-methylpyridine proceeded via formation of 1:1 and 1:2 adducts, and also formed a very stable ion-pair complex, Eu(tta) ${ }_{4} \mathrm{HB}^{+}$. When phenylpyridines were used instead of pyridine, it has been reported [22] that the adduct formation constants increased with increasing atomic number for the lighter lanthanides and thereafter decreased with increasing atomic number, although the difference was not large. If it is correct that the largest synergistic effect appears for a certain Ln(III), it may be applied to the separation of this $\operatorname{Ln}($ III) from other $\operatorname{Ln}(\mathrm{III})$. Thus, the aim of the present work was to study the synergistic extraction of $\operatorname{Ln}(\mathrm{III})$ with $\mathrm{Htta}$ and pyridine into $\mathrm{CHCl}_{3}$ in more detail.

\section{Experimental}

\subsection{Reagents}

All reagents were of analytical grade. 2-Thenoyltrifluoroacetone was obtained from Dojindo Laboratory. Pyridine (purity $>99.5 \%$ ) was obtained from Kanto Chemical Co., Inc. The stock chloroform solution of Htta was kept overnight after preparation, to attain the keto-enol equilibrium. Lanthanide(III) oxides (purity $>99.9 \%$ ) were purchased from the following companies : Shin-Etsu Chemical Co. (lanthanum, praseodymium, samarium, gadolinium, and terbium), Mitsuwa Chemicals (dysprosium, holmium, erbium, thulium, ytterbium, and lutetium), Nacalai Tesque (neodymium), and Soekawa Chemicals (europium). Chloroform was washed with deionized water prior to use. Sodium perchlorate was prepared from sodium carbonate and perchloric acid, and recrystallized three times from deionized water. Other reagents were employed without purification. The $\operatorname{Ln}(\mathrm{III})$ aqueous solutions were prepared by dissolving the respective oxide in a little excess of perchloric acid. The exact concentration of $\mathrm{Ln}(\mathrm{III})$ was determined by titration with EDTA solution at $\mathrm{pH} 5$ using Xylenol Orange as the indicator. 


\subsection{Procedures}

Most experiments were performed in a thermostatted room at $298 \pm 1 \mathrm{~K}$. The anion concentration in all aqueous solutions was adjusted to $0.1 \mathrm{M}\left(1 \mathrm{M}=1 \mathrm{~mol} \mathrm{dm}^{-3}\right)$ with sodium perchlorate. Eight milliliters of chloroform solution containing Htta and/or pyridine and an identical volume of the aqueous solution containing $\operatorname{Ln}(\mathrm{III})$ of $6 \times 10^{-4} \mathrm{M}$ was placed in a stoppered glass tube. Both phases were shaken vigorously for an hour and then centrifuged. The hydrogen ion concentration at equilibrium was measured potentiometrically using a solution containing $0.0100 \mathrm{M}$ perchloric acid and $0.09 \mathrm{M}$ sodium perchlorate as the $\mathrm{pC}_{\mathrm{H}}$ standard $\left(\mathrm{pC}_{\mathrm{H}}=-\log \left[\mathrm{H}^{+}\right]\right)=2.00$. The lanthanides(III) extracted into chloroform were back-extracted into $0.1 \mathrm{M}$ perchloric acid and then the concentration in the strip liquor was measured by inductively coupled plasma atomic emission spectroscopy (ICP-AES, SEIKO INS. SPS7000A). The concentration remaining in the aqueous phase was obtained as the balance between the initial concentration added and the concentration in the organic phase at equilibrium. The total concentration ratio of $\operatorname{Ln}(\mathrm{III})$ between both phases was denoted as the distribution ratio, $D=[\operatorname{Ln}(\mathrm{III})]_{\mathrm{o}, \text { total }}[\mathrm{Ln}(\mathrm{III})]_{\mathrm{a}, \text { total }}$, where the subscript "o" shows the species in the organic phase and the subscript "a" shows the species in the aqueous phase. The "a" will be omitted hereafter.

\section{Results and Discussion}

\subsection{Extraction of lanthanides(III) with Htta in the absence of pyridine}

When $\mathrm{Ln}(\mathrm{III})$ is extracted with various amounts of Htta in the absence of pyridine over the $\mathrm{pC}_{\mathrm{H}}$ range: 3.96 - $4.10(\mathrm{La}), 3.53$ - $3.76(\mathrm{Pr}), 3.50$-3.59 $(\mathrm{Nd}), 3.26$ - $3.33(\mathrm{Sm}), 3.08$ - 3.20(Eu), 3.24 3.30 (Gd), 3.14 - 3.19 (Tb), 3.02 -3.10 (Dy), 3.13 - 3.30 (Ho), 3.00 - 3.11(Er), 2.93 - 2.99 (Tm), 2.88 $2.94(\mathrm{Yb})$, and $2.87-2.91(\mathrm{Lu})$, the plot of $\log D$ as a function of $\log \left[\mathrm{A}^{-}\right]\left(\mathrm{A}^{-}\right.$represents $\left.\mathrm{tta}^{-}\right)$gave straight lines with slopes of +3 . This shows that the dominant species are $\mathrm{LnA}_{3}$ in chloroform and $\mathrm{Ln}^{3+}$ in the aqueous phase, although $\operatorname{Ln}(\mathrm{III})$ may form cationic chelates such as $\mathrm{LnA}^{2+}$ and $\mathrm{LnA}_{2}{ }^{+}$with the tta ${ }^{-}$anion in the aqueous phase. Then, since $D$ is represented as $\left[\mathrm{LnA}_{3}\right]_{0} /\left[\mathrm{Ln}^{3+}\right]$, the extraction constant, $K_{\text {ex30 }}$, represented by the following equilibrium, $\mathrm{Ln}^{3+}+3 \mathrm{~A}^{-} \rightleftharpoons \mathrm{LnA}_{3(0)}$ can be calculated from $D$ and $\left[\mathrm{A}^{-}\right]$:

$$
K_{\mathrm{ex} 30}=D\left[\mathrm{~A}^{-}\right]^{-3}
$$

where the concentration of $\mathrm{A}^{-}$was calculated using $\mathrm{pC}_{\mathrm{H}}$, the total concentration of $\mathrm{Htta}, \mathrm{A}_{\mathrm{T}}$, the distribution constant, $K_{\mathrm{d}}$, and the acid dissociation constant, $K_{\mathrm{a}}$, as follows :

$$
\left[\mathrm{A}^{-}\right]=\mathrm{A}_{\mathrm{T}}\left\{1+\left[\mathrm{H}^{+}\right]\left(1+K_{\mathrm{d}}\right) / K_{\mathrm{a}}\right\}^{-1}
$$

The values of $K_{\mathrm{d}}$ and $K_{\mathrm{a}}$ of Htta have previously been determined as $10^{1.85}$ and $10^{-6.33}$, respectively [23]. The extraction constants obtained are listed in Table 1. 
Table 1 The extraction constants of $\operatorname{Ln}(\operatorname{tta})_{3}$ and the ion-pairs of $\operatorname{Ln}(\mathrm{III})$ with the tta ${ }^{-}$anion and pyridine

\begin{tabular}{cccc}
\hline $\operatorname{Ln}(\mathrm{III})$ & $\log K_{\text {ex } 30}$ & $\log K_{\text {ex } 31}$ & $\log K_{\text {exip }}$ \\
\hline $\mathrm{La}$ & $13.7_{0}$ & $16.5_{7}$ & $26.1_{9}$ \\
$\mathrm{Pr}$ & $15.0_{5}$ & $17.4_{5}$ & $27.8_{1}$ \\
$\mathrm{Nd}$ & $15.2_{7}$ & $16.7_{3}$ & $28.1_{3}$ \\
$\mathrm{Sm}$ & $16.0_{7}$ & $18.7_{3}$ & $28.9_{2}$ \\
$\mathrm{Eu}$ & $16.2_{5}$ & $18.3_{7}$ & $29.0_{7}$ \\
$\mathrm{Gd}$ & $16.2_{5}$ & $18.7_{3}$ & $29.0_{1}$ \\
$\mathrm{~Tb}$ & $16.6_{0}$ & 19.2 & $29.3_{1}$ \\
$\mathrm{Dy}$ & $16.7_{6}$ & $19.2_{9}$ & $29.4_{2}$ \\
$\mathrm{Ho}$ & $16.7_{4}$ & $19.3_{4}$ & $29.3_{0}$ \\
$\mathrm{Er}$ & $16.9_{3}$ & $19.4_{7}$ & $29.4_{8}$ \\
$\mathrm{Tm}$ & $17.1_{1}$ & $18.3_{0}$ & $29.5_{8}$ \\
$\mathrm{Yb}$ & $17.3_{4}$ & $19.9_{4}$ & $29.5_{2}$ \\
$\mathrm{Lu}$ & $17.3_{0}$ & $19.3_{0}$ & $29.4_{0}$ \\
\hline
\end{tabular}

\subsection{Extraction of Ln(III) with Htta and pyridine}

Figure 1 shows examples of the enhancement of the distribution ratio of $\operatorname{Ln}(\mathrm{III})$ as a function of $[\mathrm{Py}]_{\mathrm{o}}$, when $\mathrm{Ln}(\mathrm{III})$ was extracted with $0.1 \mathrm{M} \mathrm{Htta}$ and various amounts of pyridine. The $\mathrm{pC}_{\mathrm{H}}$ value was adjusted to $2.8-4.2$, in order to prevent the formation of the aqueous cationic complexes with the tta ${ }^{-}$anion. Although $\mathrm{pC}_{\mathrm{H}}$ varied, the Htta concentration in the organic phase, $[\mathrm{HA}]_{\mathrm{o}}$, was essentially kept constant. The $\mathrm{pC}_{\mathrm{H}}$ value for respective $\mathrm{Ln}(\mathrm{III})$ was adjusted to 3.98 - 4.20 (La), 3.47 - 3.72 (Pr), 3.49 - $3.67(\mathrm{Nd}), 3.18$ - $3.44(\mathrm{Sm}), 3.10$ - 3.32 (Eu), 3.11 - $3.38(\mathrm{Gd}), 3.00$ - 3.20 (Tb), 3.01 - 3.23 (Dy), 3.08 - $3.25(\mathrm{Ho}), 2.90$ - $3.13(\mathrm{Er}), 2.92-3.22(\mathrm{Tm}), 2.81-3.04(\mathrm{Yb})$, and $2.81-3.06(\mathrm{Lu})$.

For all $\mathrm{Ln}(\mathrm{III})$ studied, the extraction was enhanced with increasing pyridine concentration. The limiting slope reached +1 with increasing pyridine concentration. With decreasing pyridine concentration, the distribution ratio of $\operatorname{Ln}(\mathrm{III})$ approached the value of the extraction constant, $K_{\mathrm{ex} 30}$. This observation suggests that one molecule of pyridine is participated in the extracted species. Therefore, the extraction equilibrium in the presence of pyridine and the extraction enhancement can be described as follows:

$$
\begin{gathered}
\operatorname{LnA}_{3(0)}+\mathrm{Py}_{(\mathrm{o})} \rightleftharpoons \mathrm{LnA}_{3} \mathrm{Py}_{(\mathrm{o})} \\
\bar{\beta}_{1}=\left[\mathrm{LnA}_{3} \mathrm{Py}\right]_{\mathrm{o}} /\left(\left[\operatorname{LnA}_{3}\right]_{\mathrm{o}}[\mathrm{Py}]_{\mathrm{o}}\right)
\end{gathered}
$$




$$
\begin{aligned}
D & =\left(\left[\operatorname{LnA}_{3}\right]_{\mathrm{o}}+\left[\mathrm{LnA}_{3} \mathrm{Py}\right]_{\mathrm{o}}\right) /\left[\mathrm{Ln}^{3+}\right] \\
& =K_{\mathrm{ex} 30}\left[\mathrm{~A}^{-}\right]^{3}\left(1+\bar{\beta}_{1}[\mathrm{Py}]_{\mathrm{o}}\right)
\end{aligned}
$$

However, pyridine can accept a proton to form the pyridinium cation, and the cation may extract the anionic chelate, $\mathrm{LnA}_{4}{ }^{-}$as an ion-pair, as reported in [19-21]. If the ion-pair is extracted, $D\left[\mathrm{~A}^{-}\right]^{-3}$ should increase with increasing Htta concentration. The equilibrium and the extraction constant of the ion-pairs are represented as follows:

$$
\begin{gathered}
\mathrm{Ln}^{3+}+\mathrm{H}^{+}+4 \mathrm{~A}^{-}+\mathrm{Py}_{(\mathrm{o})} \rightleftharpoons(\mathrm{HPy})^{+} \mathrm{LnA}_{4}^{-}(\mathrm{o}) \\
K_{\text {exip }}=\left[(\mathrm{HPy})^{+} \mathrm{LnA}_{4}^{-}\right]_{\mathrm{o}}\left(\left[\mathrm{Ln}^{3+}\right]\left[\mathrm{H}^{+}\right]\left[\mathrm{A}^{-}\right]^{4}[\mathrm{Py}]_{\mathrm{o}}\right)^{-1}
\end{gathered}
$$

while the enhancement of the distribution ratio can be represented as:

$$
D=\left(\left[\mathrm{LnA}_{3}\right]_{\mathrm{o}}+\left[\mathrm{LnA}_{3} \mathrm{Py}_{\mathrm{o}}+\left[(\mathrm{HPy})^{+} \operatorname{LnA}_{4}^{-}\right]_{\mathrm{o}}\right) /\left[\mathrm{Ln}^{3+}\right]\right.
$$

Introducing $K_{\text {ex } 30}, K_{\text {exip }}, K_{\mathrm{a}}$ and $K_{\mathrm{d}}$ for Htta into Eq. (6) yields:

$$
D\left[\mathrm{~A}^{-}\right]^{-3}=K_{\mathrm{ex} 30}+K_{\mathrm{ex} 30} \bar{\beta}_{1}[\mathrm{Py}]_{\mathrm{o}}+K_{\mathrm{exip}} K_{\mathrm{a}} K_{\mathrm{d}}^{-1}[\mathrm{Py}]_{\mathrm{o}}[\mathrm{HA}]_{\mathrm{o}}
$$

The formation equilibrium of the ion-pair and its formation constant can also be represented as:

$$
\begin{aligned}
\mathrm{LnA}_{3(\mathrm{o})} & +\mathrm{HA}_{(\mathrm{o})}+\mathrm{Py}_{(\mathrm{o})} \rightleftharpoons(\mathrm{HPy})^{+} \operatorname{LnA}_{4(\mathrm{o})}^{-} \\
\overline{\beta^{\prime}} & =\left[(\mathrm{HPy})^{+} \operatorname{LnA}_{4}^{-}\right]_{\mathrm{o}}\left(\left[\operatorname{LnA}_{3}\right]_{\mathrm{o}}[\mathrm{HA}]_{\mathrm{o}}[\mathrm{Py}]_{\mathrm{o}}\right)^{-1}
\end{aligned}
$$

and the ion-pair formation constant $\overline{\beta^{\prime}}$ is correlated with the extraction constants, $K_{\text {exip }}$ and $K_{\text {ex30, }}$, as follows :

$$
\overline{\beta^{\prime}}=\left(K_{\text {exip }} / K_{\text {ex30 }}\right) \times\left(K_{\mathrm{a}} / K_{\mathrm{d}}\right)
$$

Accordingly, Eq. (7) can be rewritten as:

$$
D\left[\mathrm{~A}^{-}\right]^{-3}=K_{\mathrm{ex} 30}\left\{1+[\mathrm{Py}]_{\mathrm{o}}\left(\bar{\beta}_{1}+\bar{\beta}^{\prime}[\mathrm{HA}]_{\mathrm{o}}\right)\right\}
$$

Since the data in Fig. 1 were measured at constant Htta concentration, $\bar{\beta}_{1}$ and $\overline{\beta^{\prime}}$ can not be determined separately. Hence, the distribution ratio as a function of $[\mathrm{HA}]_{\mathrm{o}}$ at constant $[\mathrm{Py}]_{\mathrm{o}}$ was measured. Figure 2 shows several examples of the extraction enhancement of $\operatorname{Ln}(\mathrm{III})$ in the presence of pyridine as a function of Htta concentration in chloroform. The limiting slope approaches +1 . This suggests that the extracted species is related to 4 molecules of Htta. With decreasing Htta concentration, $\log D\left[\mathrm{~A}^{-}\right]^{-3}$ approaches a constant value. The constant value is $\log K_{\mathrm{ex} 30}\left(1+\bar{\beta}_{1}[\mathrm{Py}]_{\mathrm{o}}\right)$, as indicated in Eq. (4).

Since pyridine dissolves somewhat easily and can associate with a proton in the aqueous phase, the pyridine concentration in $\mathrm{CHCl}_{3}$ at equilibrium, $[\mathrm{Py}]_{0}$, was calculated using the equilibrium constants, $K_{\mathrm{a}, \mathrm{Py}}$ and $K_{\mathrm{d}, \mathrm{Py}}$ for pyridine, as well as the total concentration of pyridine, $\mathrm{Py}_{\mathrm{T}}$, and $\mathrm{pC}_{\mathrm{H}}$ as :

$$
\mathrm{Py}_{\mathrm{T}}=[\mathrm{Py}]_{\mathrm{o}}+[\mathrm{Py}]+\left[\mathrm{HPy}^{+}\right]
$$




$$
[\mathrm{Py}]_{\mathrm{o}}=\mathrm{Py}_{\mathrm{T}} K_{\mathrm{d}, \mathrm{Py}}\left(1+K_{\mathrm{d}, \mathrm{Py}}+\left[\mathrm{H}^{+}\right] / K_{\mathrm{a}, \mathrm{Py}}\right)^{-1}
$$

The values of the distribution constant and the dissociation constant of pyridine, $K_{\mathrm{d}, \mathrm{Py}}$ and $K_{\mathrm{a}, \mathrm{Py}}$, were $10^{1.20}$ and $10^{-5.22}$, respectively [22]. As pyridine exists partially as $\mathrm{LnA}_{3} \mathrm{Py}$ and $\mathrm{LnA}_{4}{ }^{-}(\mathrm{HPy})^{+}$, the concentration of these species should be added into Eqs (11) and (12). However, even when each $\mathrm{Ln}(\mathrm{III})$ was extracted with $\mathrm{Htta}$ in the absence of $\mathrm{Py}$, the concentration was $1 \times 10^{-5} \mathrm{M}$ at maximum under the experimental conditions. In the presence of Py, the distribution ratio was enhanced and the degree of the enhancement was larger for light Ln(III). For example, the extraction enhancement of $\mathrm{Nd}(\mathrm{III})$, as shown in Fig. 1-a, is at most 7 times at $10^{-3} \mathrm{M}$ Py concentration. Then, the concentration of $\left(\left[\mathrm{LnA}_{3} \mathrm{Py}\right]+\left[\mathrm{LnA}_{4}^{-}(\mathrm{HPy})^{+}\right]\right)$can be estimated as $\leq 7 \times 10^{-5} \mathrm{M}$ so that the concentration of Py may be underestimated by a factor of $7 \%$ at maximum. The deviation from the correct concentration should be less at lower Py concentrations, because the extracted Ln(III) accompanied with Py as well as the total $\mathrm{Ln}(\mathrm{III})$ concentration in the organic phases decreases. Also at $10^{-3} \mathrm{M} \leq[\mathrm{Py}]_{\mathrm{o}}$, because of the increase in free $[\mathrm{Py}]_{\mathrm{o}}$, the proportion of Py extracted with Ln(III) should decrease. Because of the above mentioned reasons, we used Eq. (12) to calculate the free Py concentration at equilibrium.

It was not easy to keep [Py $]_{0}$ constant, because when the concentration of Htta changed, the $\mathrm{pC}_{\mathrm{H}}$ also changed. Consequently, [Py $]_{0}$ could not be kept constant. For example, when gadolinium(III) was extracted using $2.6 \times 10^{-2} \mathrm{M}$ pyridine and $0.18-2.5 \times 10^{-2} \mathrm{M}$ Htta, the $\mathrm{pC}_{\mathrm{H}}$ changed from 3.40 to 3.26. Hence $[\mathrm{Py}]_{\mathrm{o}}$ decreased to $(5.0-3.8) \times 10^{-3} \mathrm{M}$. To analyze the data on the basis of Eq. (10), only the data obtained at $\log [\mathrm{Py}]_{\mathrm{o}}=-2.33 \pm 0.02$ were used. Figure 2 shows the relation represented with Eq. (10) between $D\left[\mathrm{~A}^{-}\right]^{-3}$ and the concentration of Hpta in the organic phase under such experimental condition. Since the limiting slope is +1 , Eq. (10) should be accepted. The data in Figs. 1 and 2 were analyzed on the basis of Eq. (10), that is, using the data in Fig. 1, the term $\left(\bar{\beta}_{1}+\bar{\beta}^{\prime}[\mathrm{HA}]_{\mathrm{o}}\right)$ could be determined where $[\mathrm{HA}]_{\mathrm{o}}$ was known. The value of $\overline{\beta^{\prime}}$ was determined to fit with all the data in Fig. 2 while maintaining the value of $\left(\bar{\beta}_{1}+\bar{\beta}^{\prime}[\mathrm{HA}]_{\mathrm{o}}\right)$, through a trial and error process by using many combinations of $\bar{\beta}_{1}$ and $\overline{\beta^{\prime}}$. To get more reliable constants, similar experiments were performed for certain $\mathrm{Ln}(\mathrm{III})$ using different $[\mathrm{Py}]_{0}$. Typical examples are shown in Fig. 2. For other $\operatorname{Ln}(\mathrm{III})$, similar experiments were performed. The adduct formation constants and the ion-pair formation constants obtained are listed in Table 2. The solid curves in Figs. 1 and 2 are drawn by using the constants in Tables 1 and 2. Since the curves fit the data, the values of the constants appear reasonable.

The plot of the adduct formation constants, $\log \bar{\beta}_{1}$ and $\log \bar{\beta}^{\prime}$, in Table 2 as a function of the atomic number of lanthanides is shown in Fig. 3 together with the constants for the $\mathrm{LnA}_{3}$ adducts with 

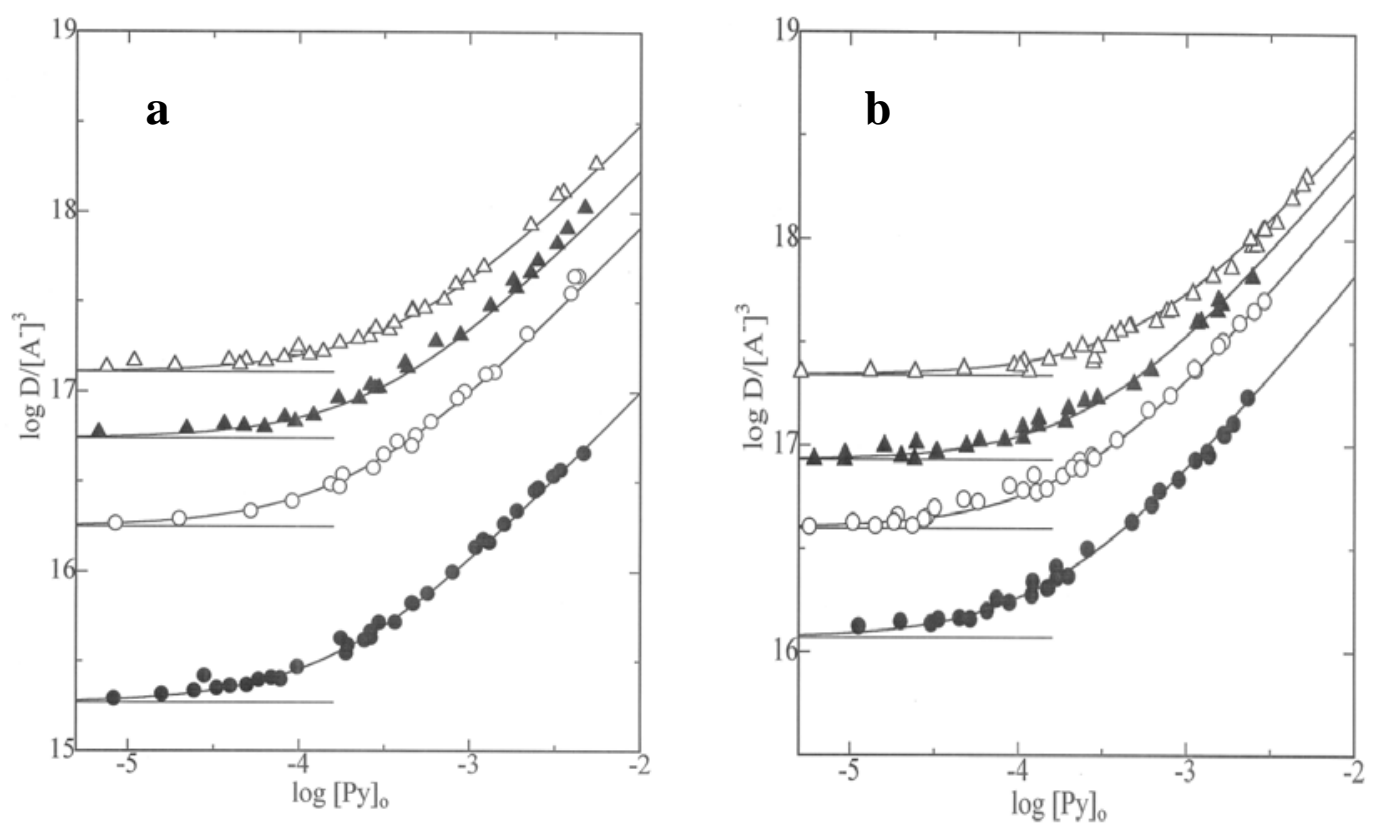

Fig. 1 Effects of the pyridine concentration in $\mathrm{CHCl}_{3}$ on the extraction of $\mathrm{Ln}(\mathrm{III})$ with $0.1 \mathrm{M} \mathrm{Htta}$.

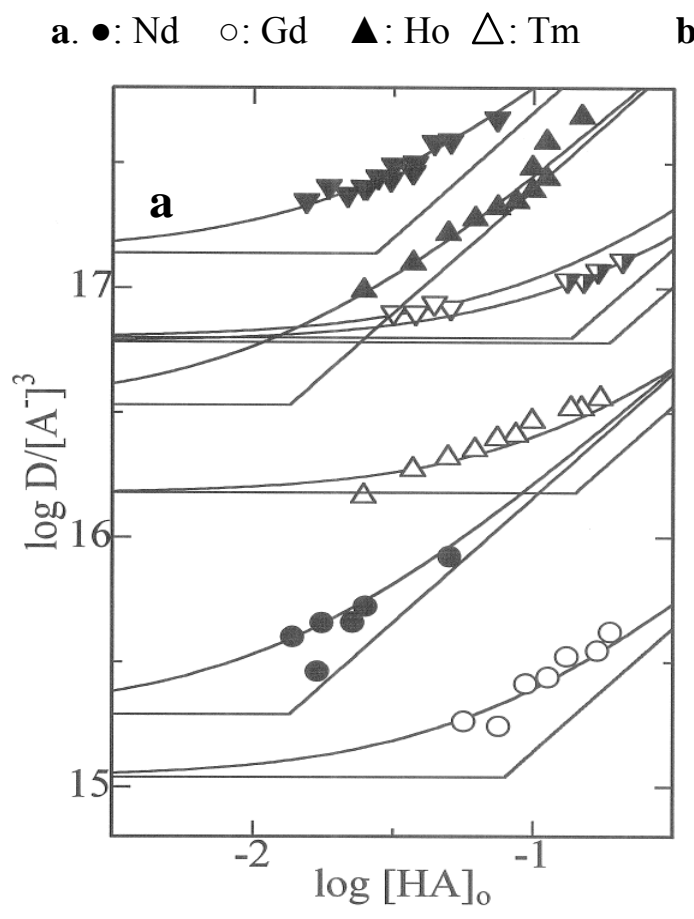

b. •: $\mathrm{Sm} \quad \circ: \mathrm{Tb} \quad \boldsymbol{\Delta}: \mathrm{Er} \quad \triangle: \mathrm{Yb}$

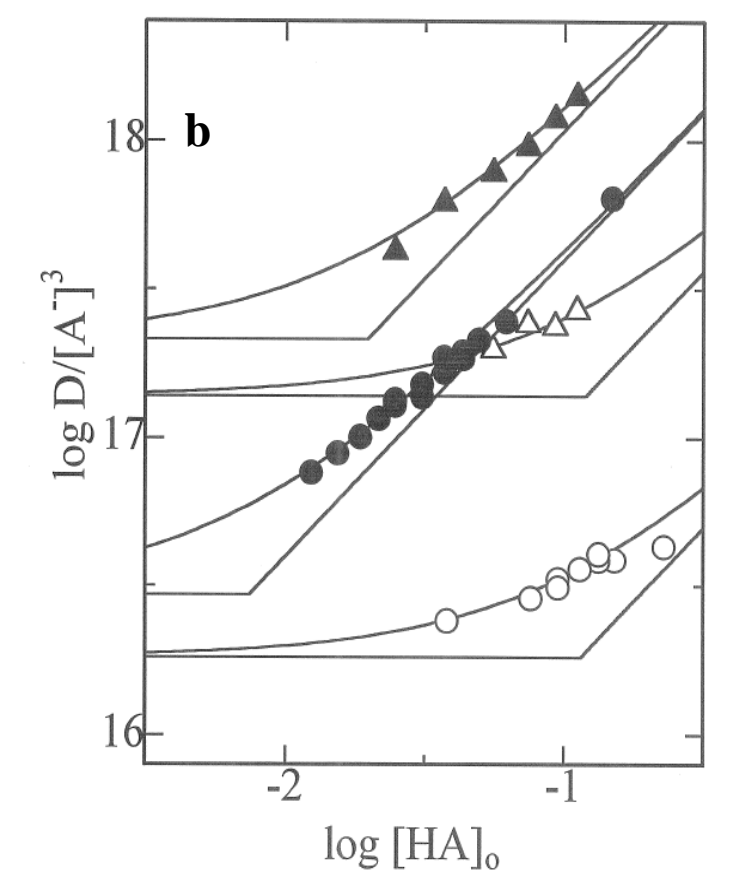

Fig. 2 Effects of the $\mathrm{Htta}$ concentration in $\mathrm{CHCl}_{3}$ on the extraction of $\mathrm{Ln}(\mathrm{III})$ at constant pyridine concentration.
a. $[\mathrm{Py}]_{\mathrm{o}} \bullet: \mathrm{e} .8 \times 10^{-3} \mathrm{M} \circ: 3.6 \times 10^{-4} \mathrm{M}$ for $\operatorname{Pr}(\mathrm{III})$,
$\Delta: 4.7 \times 10^{-3} \mathrm{M} \quad \triangle: 2.0 \times 10^{-4} \mathrm{M}$ for $\mathrm{Gd}(\mathrm{III})$
$\boldsymbol{\nabla}: 3.9 \times 10^{-3} \mathrm{M} \quad \nabla: 3.5 \times 10^{-4} \mathrm{M} \quad \nabla: 2.5 \times 10^{-4} \mathrm{M}$ for $\mathrm{Ho}(\mathrm{III})$
b. $[\mathrm{Py}]_{0} \quad \bullet: 5.1 \times 10^{-3} \mathrm{M} \quad \circ: 2.0 \times 10^{-4} \mathrm{M}$ for $\mathrm{Eu}(\mathrm{III})$
$\Delta: 4.3 \times 10^{-3} \mathrm{M} \triangle: 4.6 \times 10^{-4} \mathrm{M}$ for $\mathrm{Tm}(\mathrm{III})$ 
Table 2 The extraction constants of $\operatorname{Ln}(\mathrm{tta})_{3}$ and the ion-pairs of $\operatorname{Ln}(\mathrm{III})$ with the tta ${ }^{-}$anion and pyridine.

\begin{tabular}{ccc}
\cline { 2 - 3 } $\operatorname{Ln}(\mathrm{III})$ & $\log \bar{\beta}_{1}$ & $\log \bar{\beta}^{\prime}$ \\
\hline $\mathrm{La}$ & $2.8_{7}$ & $4.3_{1}$ \\
$\mathrm{Pr}$ & $2.4_{0}$ & $4.5_{8}$ \\
$\mathrm{Nd}$ & $1.4_{6}$ & $4.6_{8}$ \\
$\mathrm{Sm}$ & $2.6_{6}$ & $4.6_{7}$ \\
$\mathrm{Eu}$ & $2.1_{2}$ & $4.6_{4}$ \\
$\mathrm{Gd}$ & $2.4_{8}$ & $4.5_{8}$ \\
$\mathrm{~Tb}$ & $2.6_{0}$ & $4.5_{3}$ \\
$\mathrm{Dy}$ & $2.5_{1}$ & $4.4_{8}$ \\
$\mathrm{Ho}$ & $2.6_{0}$ & $4.3_{8}$ \\
$\mathrm{Er}$ & $2.5_{4}$ & $4.3_{7}$ \\
$\mathrm{Tm}$ & $2.1_{9}$ & $4.2_{9}$ \\
$\mathrm{Yb}$ & $2.6_{0}$ & $4.0_{0}$ \\
$\mathrm{Lu}$ & $2.0_{0}$ & $3.9_{2}$ \\
\hline
\end{tabular}

$\left.\left.\bar{\beta}_{1}=\left[\operatorname{LnA}_{3} \mathrm{Py}\right]_{\mathrm{o}}\left(\left[\operatorname{LnA}_{3}\right]_{\mathrm{o}}[\mathrm{Py}]_{\mathrm{o}}\right)^{-1} \quad \overline{\beta^{\prime}}=\left[(\mathrm{HPy})^{+} \operatorname{LnA}_{4}\right]_{0}\right]_{0}\left([\operatorname{LnA}]_{3}\right]_{\mathrm{o}}[\mathrm{Py}]_{\mathrm{o}}[\mathrm{HA}]_{\mathrm{o}}\right)^{-1}$

phenylacetic acid [4]. Although the values of $\bar{\beta}_{1}$ are somewhat erroneous, the trend is similar to that for phenylacetic acid, that is, the adduct formation constants appear to decrease with increasing atomic number. Such a trend was also observed for the first adduct formation constants with various carboxylic acids [4,5]. The formation constants of the adducts of $\mathrm{LnA}_{3}$ with pyridine are smaller than that with phenylacetic acid across the series, corresponding to a larger affinity for O-donors for the lanthanides(III) than for N-donors. Steric hindrance may also be involved in the interaction between $\mathrm{LnA}_{3}$ and pyridine, i.e., the $\mathrm{O}$-donor atom in phenylacetic acid is not part of the benzene ring, while the pyridine $\mathrm{N}$-donor atom is in the aromatic ring.

The formation constants of the ion-pair between the pyridinium cation and the $\mathrm{LnA}_{4}{ }^{-}$anions are also plotted in Fig. 3. The constants increase with increasing atomic number from lanthanum to neodymium, and then they decrease. This trend is different from that of the adducts, $\mathrm{LnA}_{3} \mathrm{~B}$. The difference in the variation of the constants between the adducts and the ion-pairs can be attributed to 


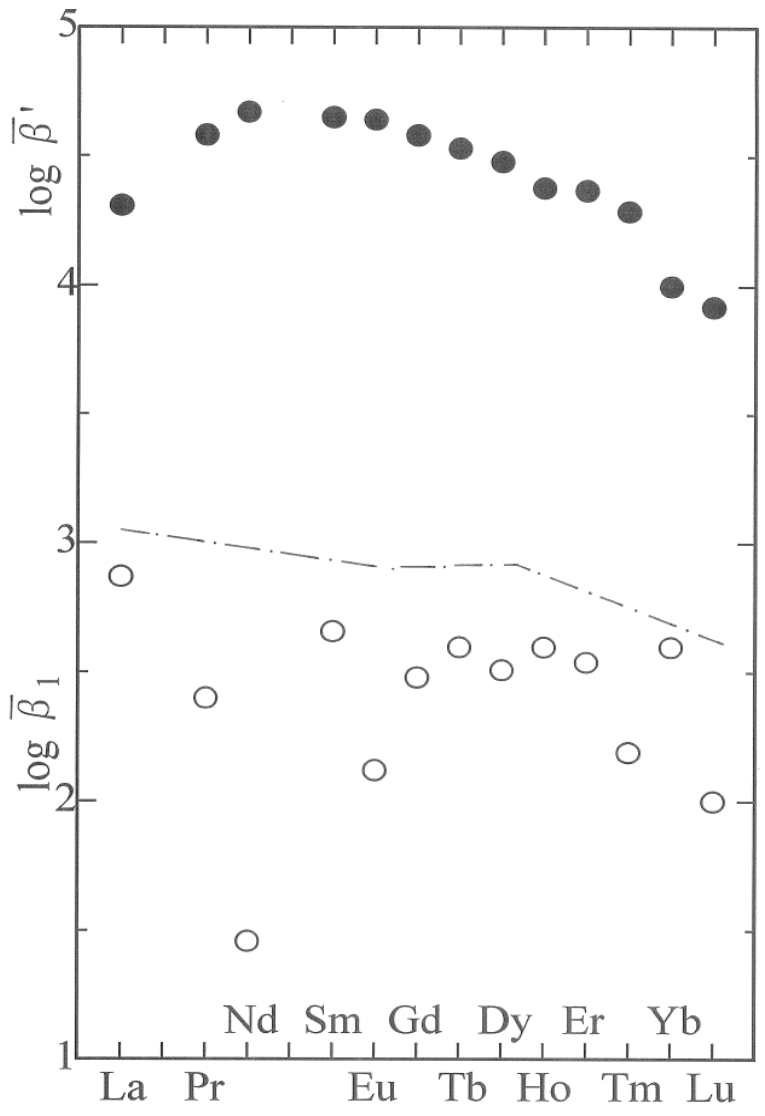

Fig. 3 Formation constants for the ion-pairs (•) and the adduct (०) of $\operatorname{Ln}\left(\right.$ III) with tta $^{-}$ and pyridine

The chain curve gives the formation constants of the adduct of $\operatorname{Ln}(\mathrm{tta})_{3}$ with phenylacetic acid [4].

the difference between unidentate pyridine and bidentate Htta. To form a more stable chelate anion, $\mathrm{LnA}_{4}^{-}$, with the interaction between $\mathrm{LnA}_{3}$ and tta anion, the larger size plus a larger coordination number should be more favorable. Light lanthanides(III) have a coordination number (CN) of 9 and heavy lanthanides(III) have a $\mathrm{CN}$ of 8 . The proportion of $\mathrm{CN}$ between 9 and 8 varies in the middle of the lanthanide series. When the coordination number changes from 9 to 8 on chelation, all water molecules still coordinated to $\mathrm{LnA}_{3}$ should be released from the lanthanides(III). It was reported that the number of water molecules coordinated to $\mathrm{LnA}_{3}$ increased from $\mathrm{La}(\mathrm{III})$ to the middle of the series and then gradually decreased [24]. Consequently, the formation of the chelate anion for light lanthanides would provide a favorable entropy change. With increasing atomic number, the ability to accept the extra ligand would be weakened. As a result, the constants will increase from La(III) to $\mathrm{Nd}(\mathrm{III})$ and then they decrease.

The extraction of the ion-pair consisting of $\mathrm{HB}^{+}$and $\mathrm{LnA}_{4}{ }^{-}$differs from that for $\mathrm{Ln}(\mathrm{III})$ with $\mathrm{Htta}$ and crown ethers. The extraction of the cationic chelate of $\operatorname{Ln}(\mathrm{III})$ involving Htta has been reported in 
the presence of crown ethers $(\mathrm{CE})$, as $\mathrm{LnA}_{2}(\mathrm{CE})^{+} \mathrm{X}^{-}$where $\mathrm{X}^{-}$is an inorganic anion $[12,13,15]$. As described in the Introduction section, amines including pyridine accept protons and may extract the $\mathrm{LnA}_{4}{ }^{-}$anion. The examples of the extraction of $\mathrm{Ln}(\mathrm{III})$ with $\mathrm{Htta}$ and trioctylamine $\left(\mathrm{R}_{3} \mathrm{~N}\right)$ as $\mathrm{LnA}_{3}\left(\mathrm{R}_{3} \mathrm{~N}\right) \mathrm{HA}$ in addition to the $\mathrm{LnA}_{3}$ adducts with $\mathrm{R}_{3} \mathrm{~N}$ have also been reported $[25,26]$. In the extraction of $\mathrm{Eu}(\mathrm{III})$ with quinoline(B) and $\mathrm{Htta}$ into $\mathrm{CHCl}_{3}$, only $\mathrm{EuA}_{3} \mathrm{~B}$ was reported as the adduct [3]. The extraction constants for $\mathrm{LnA}_{4}{ }^{-} \mathrm{BH}^{+}$can not be distinguished from the ion-pair, $(\mathrm{HB})^{+} \mathrm{LnA}_{4}{ }^{-}$or from the mixed adducts with pyridine and $\mathrm{Htta}, \mathrm{LnA}_{3} \mathrm{BHA}$. However, pyridine which is more basic than ketones or carboxylic acids can form the pyridinium ion more easily and the cation can extract the anionic chelates of lanthanides(III) as ion-pairs. This is also supported by a study on the preparation of ion-pair crystals between the piperazinium ion and tetrakis( $\beta$-diketonato)europium(III), although the salt may dissociate into two ions and neutral $\mathrm{LnA}_{3}$ [27] and also by a proton $\mathrm{nmr}$ study which showed that 2-methylpyridine forms a stable ion-pair complex, $\mathrm{Eu}(\mathrm{tta})_{4}{ }_{4} \mathrm{BH}^{+}$[21].

Figure 4 shows the variation of the proportion of the extracted species for several Ln(III) (La, $\mathrm{Tb}$, and $\mathrm{Lu}$ ) as a function of the concentration of Htta calculated using the formation constants. The figure shows that at higher Htta concentrations, the proportion of the ion-pair for all lanthanides(III) increases, but at lower Htta concentrations, the dominant extracted species is $\mathrm{LnA}_{3}$ and the neutral
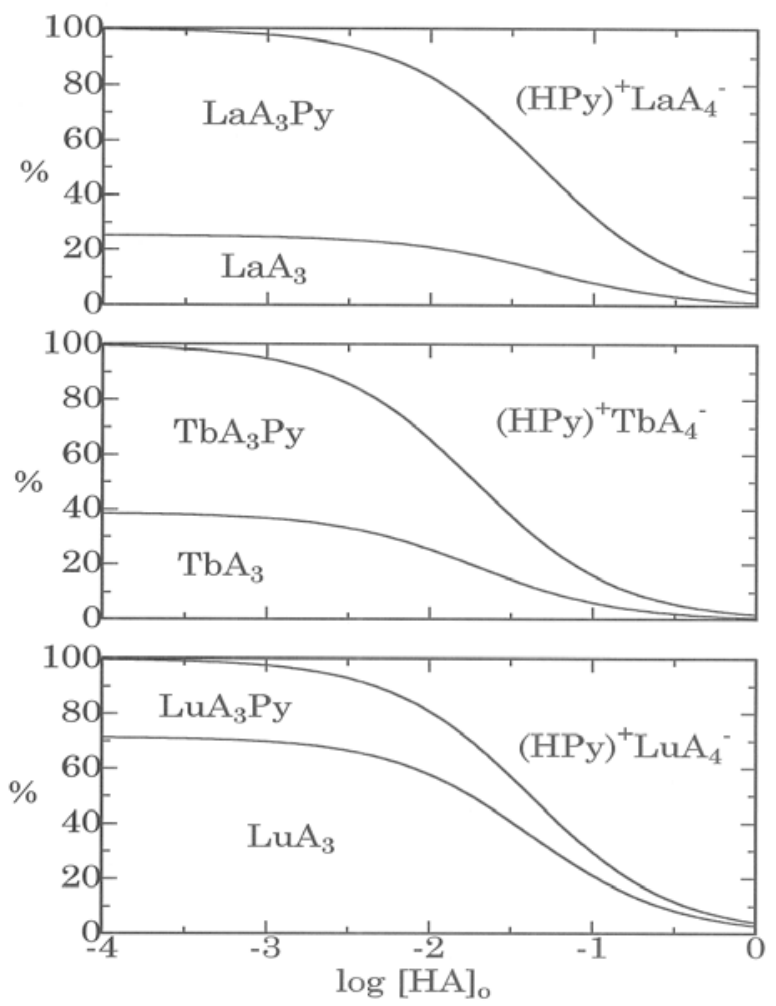

Fig. 4. Proportion of the extracted species of $\operatorname{Ln}(\mathrm{III})$ in the presence of $4 \times 10^{-3} \mathrm{M}$ pyridine as a function of the Htta concentration. 
adduct, $\mathrm{LnA}_{3} \mathrm{Py}$. As described in the Introduction section, although the different type of the extracted species in the extraction of $\operatorname{Ln}(\mathrm{III})$ with $\mathrm{Htta}$ and pyridines have been reported, the dominant species depend on the $\mathrm{pH}$, the Htta concentration, and the pyridine concentration. All the extracted species should be correct under the experimental conditions studied. For example, in the study [17] in which $\mathrm{LnA}_{3} \mathrm{Py}$ as well as $\mathrm{LnA}_{3} 2 \mathrm{Py}$ were reported as $\mathrm{LnA}_{3}$ adducts, the Htta concentration was lower, i. e., $\mathrm{A}_{\mathrm{T}}$ $=10^{-4}-10^{-2} \mathrm{M}$, and $\mathrm{B}_{\mathrm{T}}=10^{-3}-10^{-1} \mathrm{M}$. As seen from the comparison with Fig. 4, the ion-pairs are not important.

However, the present results show that, for quantitative data analysis of the synergistic extraction with a $\beta$-diketone and a Lewis base such as pyridine, the variation of the distribution ratio should be correlated with the $\beta$-diketone concentration as well as the $\mathrm{pH}$ and the Lewis base concentration.

The separation factor for the ion-pairs which can be calculated as the ratio of $K_{\text {exip }}$ between two $\mathrm{Ln}(\mathrm{III})$ is similar to that for $K_{\mathrm{ex} 30}$ for all lanthanides. The separation factor involving the adduct, $\mathrm{LnA}_{3} \mathrm{Py}$, among the light lanthanides seems a little larger than that of $\mathrm{LnA}_{3}$. This may be a property of $\mathrm{N}$-donor ligands, because such a trend was not reported for O-donor ligands.

\section{Acknowledgement}

The present authors are grateful to express Dr. S. Yajima, Wakayama University, for her valuable discussion. They also thank to Messrs. K. Kato and M. Hagioita, Science University of Tokyo, for their experimental aid.

\section{References}

1) T. Sekine, Y. Hasegawa, "Solvent Extraction Chemistry”, Marcel Dekker, New York, 1978.

2) L. Farbu, J.Alstad, J. H. Augstson, J. Inorg. Nucl. Chem., 36, 2091 (1974).

3) T. Sekine, D. Dyrssen, J. Inorg. Nucl. Chem., 29, 1475 (1967).

4) Y. Hasegawa, T. Ohyama, S. Katsuta, Bull. Chem. Soc. Jpn., 68, 3091 (1995).

5) Y. Hasegawa, T. Yamada, K. Nagata, Solv. Extr. Ion Exch., 14, 89 (1996).

6) N. Kameta, H. Imura, Anal. Sci., 17, 957(2001).

7) N. Kameta, H. Imura, Bull. Chem. Soc. Jpn., 74, 1641(2001).

8) G. F. Gagabe, Y. Satoh, K. Satoh, K. Sawada, Bull. Chem. Soc. Jpn., 80, 2357 (2007).

9) G. F. Gagabe, K. Satoh, K. Sawada, Dalton. Trans.,5495 (2009).

10) H. F. Aly, S. Khalifa, Solv. Extr. Ion Exch., 3, 623 (1985).

11) J. M. Mathur, G. R. Choppin, Solv. Extr. Ion Exch., 11, 1 (1993).

12) Y. Kitatsuji, Y. Meguro, Z. Yoshida, Solv. Extr. Ion Exch., 13, 289 (1995).

13) Y. Meguro, Y. Kitatsuji, T. Kimura, Yoshida, J. Alloy Comp., 271-279, 790 (1998).

14) G. F. Gagabe, Y. Satoh, K. Satoh, K. Sawada, Monatsh. Chem., 137, 1015 (2006). 
15) N. Hirayama, H. Okamura, K. Kidani, H. Imura, Anal. Sci., 24, 697 (2008).

16) E. F. Kassierer, A. S. Kertes, J. Inorg. Nucl. Chem., 34, 3221 (1972).

17) S. Nakamura, N. Suzuki, Polyhedron, 7, 155 (1988).

18) S. Yajima, Y. Hasegawa, Bull. Chem. Soc. Jpn, 71, 2825 (1998).

19) B. Kuznik, L. Genov, G. Georgiev, Monatsh. Chem., 105, 1190 (1974).

20) B. Kuznik, L. Genov, G. Georgiev, Monatsh. Chem., 106, 1543 (1975).

21) J. F. Desreux, J. Massaux, G. Duyckaerts, J. Inorg. Nucl. Chem., 40, 1159 (1978).

22) Y. Hasegawa, S. Hirose, J. Yamanaka, Anal. Sci., 11, 59 (1995).

23) T. Sekine, Y. Hasegawa, N. Ihara, J. Inorg. Nucl. Chem., 35, 3968 (1973).

24) Y. Hasegawa, M. Miratsu, T. Kondo, Inorg.Chim. Acta, 303, 291 (2000).

25) L. Genov, G. Georgiev, Monatsh. Chem., 100, 1892 (1969).

26) L. Newman, P. Klotz, Inorg. Chem., 11, 2150 (1972).

27) L. R. Melby, N. J. Rose, E. Abramson, J. C. Caris, J. Amer. Chem. Soc., 86, 5117 (1964). 